\title{
Shotgun Houses and Housing Projects: Architectural typology and memory techniques of two New Orleans reconstruction scenarios ${ }^{1}$
}

\begin{abstract}
William Taylor
This world has never been short on disaster. Nevertheless, given recent events and trends in scholarly literature and popular media, one can argue that urban disasters are acquiring new and complex meanings. This situation is partly due to the global expansion of urban societies where-in "the city"-the impacts of disastrous events are most clearly recognised (Davis 2002: 360-99; Schneider \& Susser 2003). The topicality of disaster is also most likely partly due to the mix of seemingly universal 24-hour television news coverage, remote sensing and digital and novel social media that create new and ever larger publics and possibly public 'demand' for catastrophic events (Ashlin \& Ladle 2007). Making for an even more complex picture, the growth in disaster studies, drawing on these and other sources, brings an array of conceptual frameworks and concerns (like risk and urban vulnerability) to the fore. The growth in number and authority of agencies responsible for the delivery of disaster relief, mitigation and planning, and for directing reconstruction efforts, has come to impose different agenda and interventions on disaster-struck populations. These include multiple levels of government, corporate and private agencies, and NGOs.
\end{abstract}

To this mélange of different ways of knowing, representing and managing disaster, architects, planners and allied design professionals bring their own varied perspectives. Their expertise is often in competition with other authorities, with commonplace reasoning and popular belief on the best course of action following a disastrous event and, increasingly, with so-called 'community-led' design and reconstruction initiatives. Community-led design and reconstruction is problematic, practically and ethically, at the best of times (Taylor \& Levine 2011: 174-7) and made even more so when rebuilding involves different kinds of communities, and mixed public and private interests. While the stock-in-trade language of architectural and urban form may sometimes provide for common ground between these different authorities and interests, there is nothing to guarantee consensus on any single vision, urban plan or building type for the re-emergent city. This is not surprising given that all such plans are value-laden and unavoidably fraught with ethical decisions at virtually every stage.

This essay enlarges on the connection between reconstruction discourse and renewal of typological analyses. In architectural history and theory, the utility (but also imprecision) of typological methods was acknowledged by its early proponents among Enlightenment scholars and architects (Leach 2010: 62). More broadly, opportunities for categorising and formally describing material artefacts like buildings in a number of ways speak to the epistemological confines of empirical understanding in an indeterminate field. Knowledge of distinctive building forms and reasoning used to relate building types to historical and performative contexts is generated (though not always sharpened) by catastrophic episodes in which urban fabric and 'normal' ways of inhabiting it are made tenuous or entirely destroyed. Typological analysis and reconstruction strategies initiated by ascertaining the 'right' architectural forms with which to rebuild invariably highlight aspirations for civil society and these are invariably mixed. These aspirations are as likely driven by wishful thinking, false memory and hopes as by sound design plans based on competing values.
The author is grateful to Michael Levine, James O'Byrne and Oenone Rooksby for their assistance and advice while preparing this essay. Research was funded in part by a grant from the Australian Research Council. 
This essay outlines one set of case studies: two "typologies of Katrina" that informed debate over the reconstruction of New Orleans. It questions the roles that architectural type, community and memory play in these two reconstruction scenarios. Arguably, Katrina introduced a new genre of dystopia into popular and political thinking, where the failure of a society was written large. Katrina was distinctive insofar as it was less a natural catastrophe (due largely to flooding, etc) than it was a largely preventable social and political one-driven and made possible by poor decision-making (engineering, social, political/ethical) before, during and after the event. Equally, given the scale of Katrina's devastation and impact on the social imaginary, the building types proposed for the city's reconstruction acquire an even greater utopian-and hence, propositional (also 'unreal')-character for manifesting beliefs about how people are supposed to live. Historically, in Western discourse, utopian and dystopian thinking were often intertwined-the idealism of the former was seldom far from an alternative reality of seemingly insurmountable challenges-and this holds true when contemplating these two scenarios.

\section{Design for traumatised communities}

The broad literature of disaster studies suggests there are significant historical and cultural circumstances that make each disastrous episode unique. Nonetheless, historical research can articulate broad patterns of perception, reflection and choice that are characteristic of particular settings and times. When looking to recent developments, much disaster commentary-at least in Western media-has come to resemble a set of problems organised around the needs of traumatised communities. This is an object of governance and planning conceived in different ways. On the whole, it is presupposed to be an organic unity that connects urban populations, their past and place in a meaningful and socially significant manner (for example: Furedi 2007; Glavovic 2008). In August 2006, one year after Katrina, the Journal of Architectural Education dedicated a special issue to New Orleans and its reconstruction. The opening editorial includes claims presupposing enduring links between a community conceived as an organic unity, its building heritage imagined as a mnemonic vehicle, and the city's unique setting. Though largely unsupported (and perhaps unsupportable, as they are fundamentally existential assertions), the following proposition would likely find agreement across the range of disaster studies and resonate in commonplace reasoning:

The culture of New Orleans is unique. It is a mix of ancient heritage with layers and adaptations added by successive generations, resulting in a singularly beautiful cultural mosaic of elements. Hurricane Katrina destroyed buildings-though not in the city's historic core-and displaced hundreds of thousands of people, but it cannot wipe out the memories and spirit of the citizens. (Allen 2006: 4)

Allowing for civil liberties to enter this mix of ideas, the journal's editor, Barbara Allen, adds, "It is necessary to enable every citizen to come back to this exceptional city if they so desire." (2006: 4) Given that such memories and desires are not univocal-and indeed they both often contain competing visions of what was and should be after a disastrous event-it is not surprising they should result in competing expectations for reconstruction efforts.

The "right of return" for New Orleans refugee residents featured in heated debates over the city's future, alongside concerns expressed for the possible violation of rights behind what was regarded by many observers as the hasty and possibly 
unwarranted demolition of thousands of storm and flood-damaged houses during the first year after the storm (Allen 2006: 4-5). The situation of poor tenant-occupiers was in many ways even worse, their dispersal and diminished political voice making it difficult to re-assert a community's voice into local and national decision-making.

For housing activists, the situation of many New Orleaneans made for the environmental and bureaucratic (both governmental and corporate) equivalent of 'urbicide'. This is a term which circulated in the 1990s to describe the systematic destruction of urban communities and places as a strategy of war. It is typically reserved for places like Sarajevo, Mostar and Fallujah, but has a lineage reaching back to 1960s North American precedents when it signified the destructive effects of modernist urban renewal schemes (Huxtable 1972; Graham 2003). Herscher writes:

Resuscitated in the context of post-Yugoslavia's violent conflicts, however, the destruction signified by urbicide radically expanded. Against the idea that post-Yugoslav cities were destroyed because of military necessity or through collateral damage, urbicide posed the target of destruction as the city itself-as an ensemble of architecture, a community of citizens, a medium of collective memory, or even the site of civilization as such. The concept of urbicide provided a new category to conceive of political violence, a violence that could be framed as at once urban, deliberate, and illegitimate. (2006:18)

What is intriguing about claims such as Allen's and the concept of "urbicide" is a common, underlying intellectual project that subsumes psychological and sociological domains of reasoning under a distinctive experience of community, place and memory. In other words, the common belief that memory is an intrinsic part of the human condition of shock and loss gives form to a theory of how urban communities experience disaster. This seems to be problematic as it invites thinking that it is largely anachronistic, in that communities are believed to be formed partly by memories of a place, but memory is neither a collective faculty nor is it necessarily geographically bounded. Whose memories are included and whose are not? Are these truly memories of one place or do they also draw on other real or imagined places?

\section{The shotgun house}

The first typology of Katrina speaks to the ambiguous place of official histories in post-disaster reconstruction and the tendency to justify rebuilding projects as restoring communities by somehow reinstating building fabric. Writing on New Orleans rarely fails to mention the distinctive character of its timber-framed houses, including its elongated "shotgun" houses, one of the city's more ubiquitous residential building types. The shotgun has long featured in writing on the towns and rural landscapes of the southern United States, particularly the Delta region. This tendency contributes perhaps to a prevailing and overly-romanticised view of the region's past in accounts that risk downplaying some aspects of the building's history-for instance, its association with slave quarters and the slave-holding plantation system. Painting an idyllic picture of Delta life in his account of southern rural architecture (specifically, the country store), historian Thomas Clark described towns where "There was no wiser spot on earth than the porches which jutted out from the long shotgun buildings.” (1944: 56) Writing in 1974 on the state of race relations in the South, a correspondent for The Times (of London, January 
14: 12) begins by confirming a popular caricature of the region: "The American South is still unmistakably southern: words with the edges rounded off, magnolias in the front yard, grits at breakfast, blacks living in shot-gun shacks, locals nodding hello to strangers."

Scholarship on New Orleans architecture commonly emphasises the provenance of the building in the unique circumstances of the city's history and culture, and the alluvial environment of the Gulf Coast states-though varied reasons are given why so many of the houses were built there. For much of its history the Crescent City was an entity bounded, physically and conceptually, on all sides by water, with swamps and marshlands encircling only limited buildable land, particularly before the arrival of technology in the 1920s that allowed large-scale draining of wetlands and other technical, socio-economic and political developments that facilitated outward suburban development. This was where, in times past, cut from indigenous cypress forests long since buried by suburbia or from the pine woods that still stretch far to the north, reserves of timber were available to build these narrow forms that fit restricted building sites. Variations on the type, owing to the circumstances of site, family size, the measure of wealth or the personal tastes of residents, add to assessments of the city's architectural heritage. New Orleans is a place where most likely every native can distinguish between a "double shotgun" where two dwellings are attached, a "camelback shotgun" where a second floor is added at the rear of the plan, and a shotgun with a wraparound porch (Vogt 1985: 22-23).

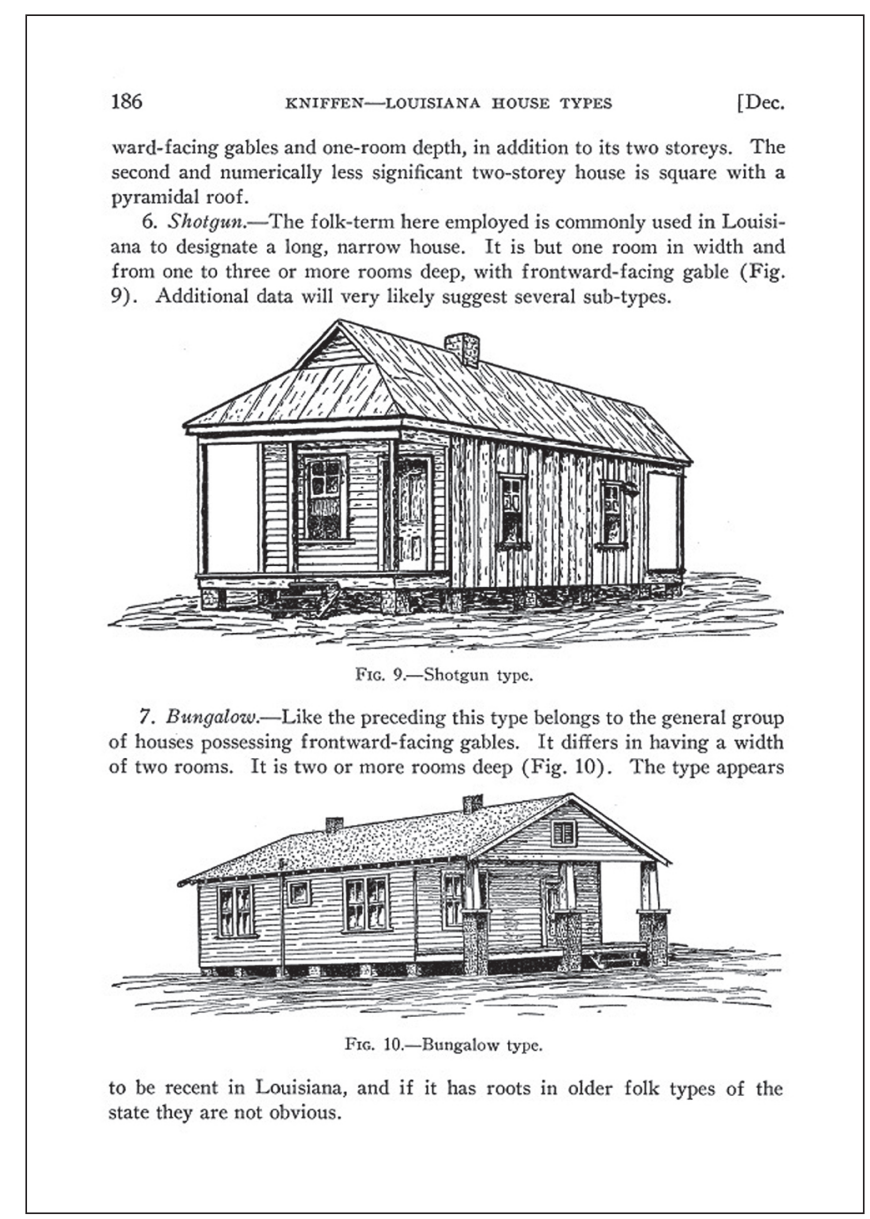

Fig 1. F. B. Kniffen, (1936). Louisiana House Types. Annals of the Association of American Geographers 24 (4) (December), p. 186 
Histories accounting for southern regional and New Orleans architecture commonly yield a partial or undiscerning view of the shotgun house. They render it as both an inherently functional building type and autochthonous or organic, growing from the roots of longstanding tradition-hence, its adoption and interpretation as a vehicle for memory. In his now classic paper "Louisiana House Types", geographer, anthropologist and folk historian Fred Kniffen constructs a typology of the state's vernacular buildings, in post-European settlement (Fig. 1), and a qualitative and quantitative mapping of its built environment he described as "culturogeographic" (1936: 179). While Kniffen's paper accounts for the number and distribution of nine Louisiana house types across the state, its descriptive narrative and maps were also, in the end, aiming to arrive at "an [aerial] expression of ideas regarding houses-a groping toward a tangible hold on the geographic expression of culture" (1936: 192). However, without a historical accounting of the sources for and history of this culture, the paper merely outlines their geo-spatial diffusion (Vlach 1976: 47-49). Seventy years after Kniffen's paper was published, designers of post-disaster housing for New Orleans searched for such a tangible "expression of culture" in their appropriation of the shotgun building type.

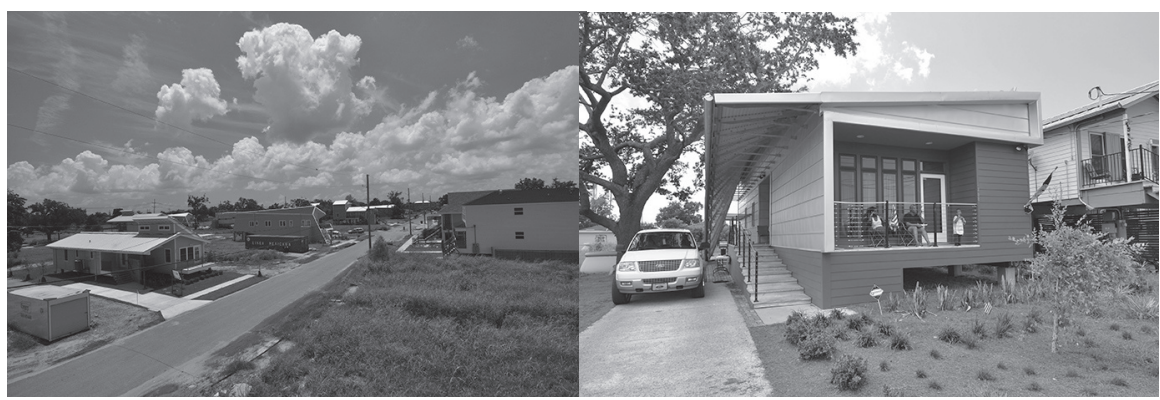

Reconstruction plans for the city's flooded districts included assorted allusions to, copies of and reinterpretations of the building type (Figs. 2 \& 3). The design competition brief for 150 new houses in the Lower Ninth Ward (where approximately 4000 houses were destroyed) sponsored by American actor Brad Pitt and his "Make It Right" foundation allowed for only two models to be emulated: single-family detached units derived from the shotgun type and "the duplex", a multi-family home. Results show wide-ranging formal interpretations of these models with added features, making both building types "modern": aesthetically innovative, and responsive to demands for ecological sustainability and twentyfirst century environmental risks:

The thirteen architects who contributed to single family home designs all hewed to the traditional New Orleans shotgun house format-simple, narrow and fashioned to fit the long skinny lots in the Lower 9th Ward. They also all include porches-a feature highly valued in the neighbourhood that places a premium on sociability and connectedness to the community. All of the homes have more complex floor plans, solar panels, rain water collectors and other green features. (Make it Right 2009: 'Building Green')

As Stephen Verderber (2010) explains, the origins of the New Orleans shotgun house may owe more to contingencies of cultural importation than any obvious and necessary organic link between a people and a place. Consequently, the building type's re-interpretation in the Lower Ninth Ward could be viewed as historically anachronistic, fundamentally impractical (particularly in Katrina's
Fig. 2. Lower Ninth Ward, New Orleans. [Photo: Kukame McKenzie (July 2010)]

Fig. 3. Project for Make It Right Foundation (MIR) in the Lower Ninth Ward, New Orleans. Trahan Architects. The architects' description of the project on the MIR website begins: "The shotgun typology is a resultant of site constraints, environmental conditions and efficient planning. The approach to the project was to identify these main characteristics and represent them in a more contemporary fashion." [Photo: Kukame McKenzie (July 2010)] 
wake) or possibly self-indulgent on the part of its architects and sponsors. Verderber cites John Vlach's 1976 study of the shotgun that challenged received wisdom regarding the building type's origins and argued that:

... in the development of the shotgun house we find an Afro-American artefact that has been adopted by Whites and effectively incorporated into popular building practices. The significance of this postulated cultural borrowing cannot be overlooked for it represents an important contribution of Afro-Americans to the cultural landscape. (Vlach 1976: 47)

This connection to African-American identity and the building type's likely historical provenance in places far removed from Louisiana, like Haiti and other Caribbean islands, does not in itself render the shotgun irrelevant as a model for reconstruction (at the time of its inundation and near complete destruction the Lower Ninth Ward of New Orleans was largely black, supporting one likely argument for the building's legitimacy). However, the building's ambiguous provenance does raise questions why one should accept prima facie the iconic status of the shotgun and privilege its continued use as a model when other features of the Ninth Ward's sociology and urban morphology were so radically altered by Katrina and the tabula rasa that followed in its wake? While many of the former residents wishing to return to New Orleans may still speak in words "with the edges rounded off" as the reporter for the Times observed in 1974, is it ideal they now be obliged to live in "shot-gun shacks" reproduced in such exotic variety?

Historical anachronism aside, there are at least two problems, neither one strictly architectural (or subject to a designer's control), with outcomes from the Make It Right scheme that are wrong for New Orleans-that work against the design brief's aspirations for "sociability and connectedness to community". Firstly, the protracted pace of reconstruction coupled with an overall redevelopment drive that must be recognised as ad hoc has resulted in the replacement of only a small number of the 4000 houses lost in the Lower Ninth Ward. Designs by international architects and competition winners sit alongside the few additional houses built by other means and the greater number of vacant, neglected and weed-ridden lots, resulting in a community that appears spread too thin and proves hard to service with public utilities, fire prevention and police services. Secondly, in the absence of agreement on a strong, centralised planning regime for the entire region-of the kind able to undertake a full range of initiatives, including the permanent depopulation and ecological restoration of some areas if necessary-commendable, but nonetheless piecemeal efforts such as Brad Pitt's will continue to apply band-aid remedies to a gaping wound. These problems render any appeal to memory as the basis of placefulness and heritage particularly tenuous.

\section{Housing projects}

The second typology of Katrina raises questions more about the buildings that are destroyed after a disastrous event and histories forgotten or only partially remembered, than about models for rebuilding per se; it raises more fears for the purposeful erasure of history than the past's reinstatement. A curious aspect of post-Katrina reconstruction was that while efforts were being undertaken to devise and build new building types responsive to the heritage of the place and its venerable stock of residential architecture, remnants of the city's public housing still standing after the storm were being torn down. At a time when much of the pre-storm population was unable to return home owing to the shortage of 
habitable accommodation, both activities-the building of neo-shotguns and further destruction of housing and its replacement by quasi-traditional buildingswere justified as means of restoring community.

Targeted for whole or part destruction before the storm, four of the city's biggest public housing estates dating from the 1940s and 1950s provided accommodation for about 3077 families. Some residential units in some parts of the older estates were subsequently flooded, but otherwise survived intact, or so it seemed to outward appearances. The solid-looking forms and brick walls of the residential blocks provided a rallying point for housing activists and some former residents protesting their demolition at a time in which emergency housing was sorely needed. This outcome figured in broader debates over the likely political alienation of the city's African-American population if the public housing estates were to be destroyed (Gardner, Irwin \& Peterson 2009). Circumstances surrounding the demolition of one estate, the Magnolia or C. J. Peete Projects located in the 11th and 12th Wards of New Orleans, are indicative of conditions impacting on the other sites.

Originally named for the tree-lined street along its northern border, the Magnolia Projects was built in 1940, then expanded and nearly doubled in size in 1955 . It was one of six public housing projects opening that year and one of four (along with the Calliope, Lafitte, and St. Bernard projects) designated for black tenants in accordance with segregationist practices of the time (the other two projects, St. Thomas and Iberville, were reserved for low-income white residents). The Magnolia Projects was conceived as part of a nationwide program formed in the 1930s aimed at alleviating the deplorable living conditions experienced by many of America's lowincome residents. On the site of the Magnolia Projects, knowledge of prevailing design standards and functional relationships for attached, single-family dwellings, coupled with cost-effective building methods and planning and construction practices exercised by national and municipal housing authorities established (in the 1930s) for the purpose, resulted in a total of 1403 standardised residential units accommodating approximately 2100 people. Mahoney writes that:

The early New Orleans projects were some of the most attractive and best constructed in the nation. They were designed as a mixture of townhouses and apartments in 2- and 3-story buildings, arranged in courtyards built around grassy lawns. Some had curving driveways. On most of the sites, trees had been preserved. (1990:1268)

Located in an uptown district commonly known as Mid-City, the site contained a significant African-American, but nonetheless mixed, population. The historical urban morphology of Mid-City was characterised in many areas by smaller-scale housing typically occupied by poorer citizens (and in some places grouped around a neighbourhood cemetery), with larger and more elaborate houses surrounding these and finally, mansions for the city's wealthy elite lining the avenues and boulevards that connected one district to another. New Orleans was racially segregated from an early date-socially, culturally and politically. Spatially, the dispersion and mix of races and classes was commonly more finely-grained than in other cities, though this heterogeneous condition was dynamic and variable. It was affected, for instance, firstly, at the larger scale of the New Orleans metropolitan area by the phenomenon of "white flight" which gained speed in the 1960s. Secondly, localised developments like the Magnolia Projects altered the racial composition of urban districts-including perceptions of the character of resident populations-providing sites for the further formation of racial and socio-economic identities as well as racial prejudices. 
The construction of the public housing estates in New Orleans contributed to a more pronounced racial, spatial and symbolic order in the city. Conceived largely as an internalised domain, the building of C. J. Peete furthered what would subsequently be called by urban sociologists the "ghettoization" of urban space. Site planning resulted in the closing of thoroughfare streets and the creation of linear parks and common yards around which the new residential buildings were grouped.

By the 1980s and 1990s, the worsening physical condition and deteriorating infrastructure of the development, as witnessed in many public housing estates across the United States, was coupled with high rates of crime and chronic unemployment among residents, alcohol and drug dependency and a host of additional social problems. In the years just before Katrina, crime rates there had become legendary. Plans to partly or wholly demolish and then redevelop the project for local residents were initiated in the 1990s, though by 2005 only the 1955 expansion had been razed. Many of the remaining buildings were vacant and fenced off when the hurricane hit and the city's failed storm defences flooded the area with between two and four feet of water and water-borne contaminants.

C. J. Peete was initiated in 1941 with an act of "slum clearance" but ended up providing rubble for a second wave of urban and social reform. By 2007, when an "Environmental Justice" report commissioned by the US Department of Housing and Urban Development delivered a comprehensive assessment of the project's physical state and future potential, the elusive goal of social reform had become further complicated. It was broadened to accommodate not only updated design standards, but ruling neo-liberal expectations for market-led redevelopment. The report found that:

The C.J. Peete Housing Development suffers from high density, overpopulated units, deteriorated buildings and infrastructure, obsolete building components, hazardous building materials, and building envelopes that are not energy efficient. Demolition and reconstruction of the Development will convert a conventional public housing development into a new, mixed-income and mixed-use community that includes

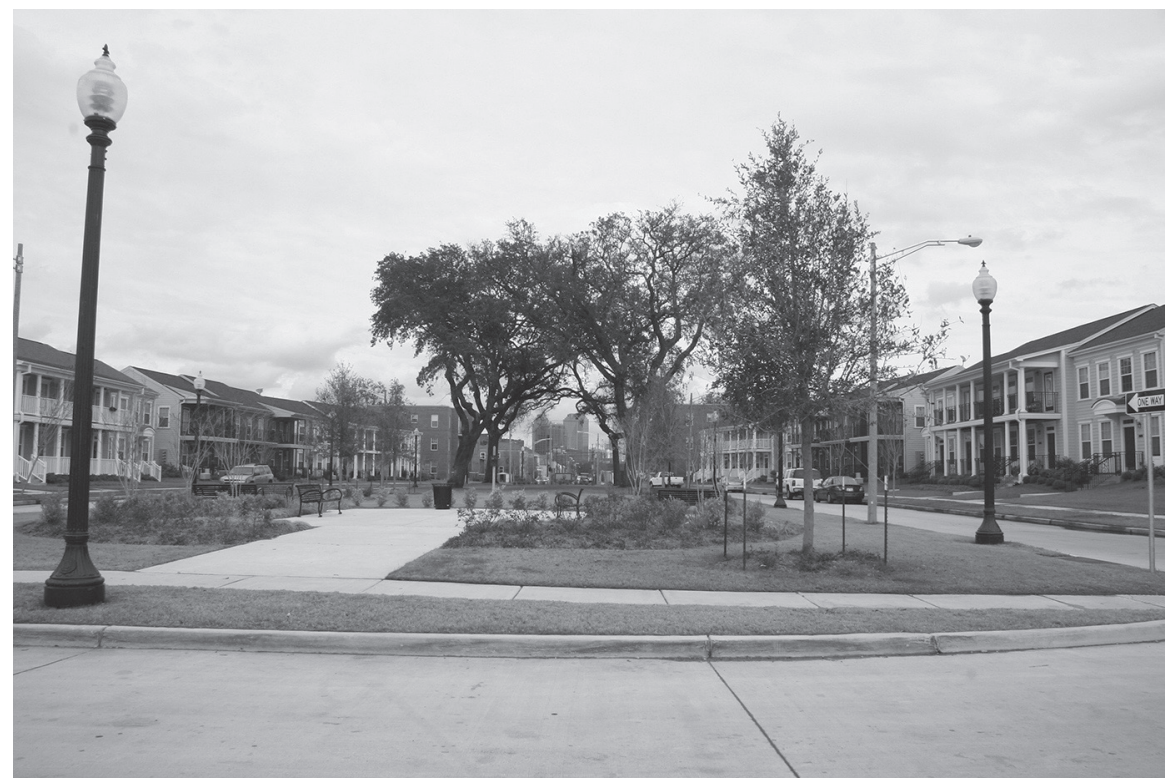


rentals and home ownership units in New Orleans. The final Master Plan must create a blueprint for a successful, stable, diverse, safe, attractive and sustainable mixed-income community. (US Department of Housing and Urban Development 2007: 12)

In a move suggestive of the marketing common in much commercial residential development, but also highlighting the desire to distance the new complexes from their impoverished, crime-ridden pasts, the four public housing estates were renamed. C. J. Peete, having acquired its name through re-christening in honour of its African-American manager who administered the estate from 1952 to 1978, was made-over a second time and called Harmony Oaks (Fig. 4). Expectations that the resulting design should satisfy multiple demands for relatively low-cost housing and market desirability, security along with consumer choice and the aesthetic trappings associated with "community", resulted in a neo-traditional architectural style common to commercial projects throughout the United States. This was sanctioned by government authorities, including the requirement that all proposed construction design have prior approval from the Louisiana State Heritage Preservation Office and the American Council on Historic Preservation. Guidelines required the "Louisiana Vernacular, Victorian, and Classical styles ... in a combination of single, double and small apartment buildings" (US Department of Housing and Urban Development 2007: 12).

A back-cover advertisement appearing in the New Yorker by investment firm and financial backer for Harmony Oaks, Goldman Sachs, reveals only part of the story behind the project:

After one of New Orleans' oldest public housing developments was devastated by Hurricane Katrina, we invested in rebuilding it from the ground up. Our Urban Investment Group partnered with an experienced developer, McCormack Baron Salazar, as well as former tenants, neighbourhood organisations, and state and local housing agencies to enable families and businesses to return home. Today, Harmony Oaks is a community where neighbours can come together-on their new front porches, at the local community center or the nearest playgrounds. (June 6, 2011)

While the condition of much New Orleans public housing was truly deplorable by September 2005, its dereliction was only partly due to Katrina and the impact of stormwater and floodwater on building fabric. Its redevelopment, though generally praised as delivering positive social outcomes (residents are reported as experiencing greatly reduced rates of crime and other improvements improvements, see Reckdahl 2006), has failed in other regards. However, this failure is not so much a consequence of physical infrastructure, or the availability of consumer "choice" allowed for by buildings for purchase or rent that are clothed in a range of historicist styles, but rather a broader range of circumstances. 
Fig. 5 Columbia Parc (formerly St. Bernard) housing estate [Photo: author, January 2012]

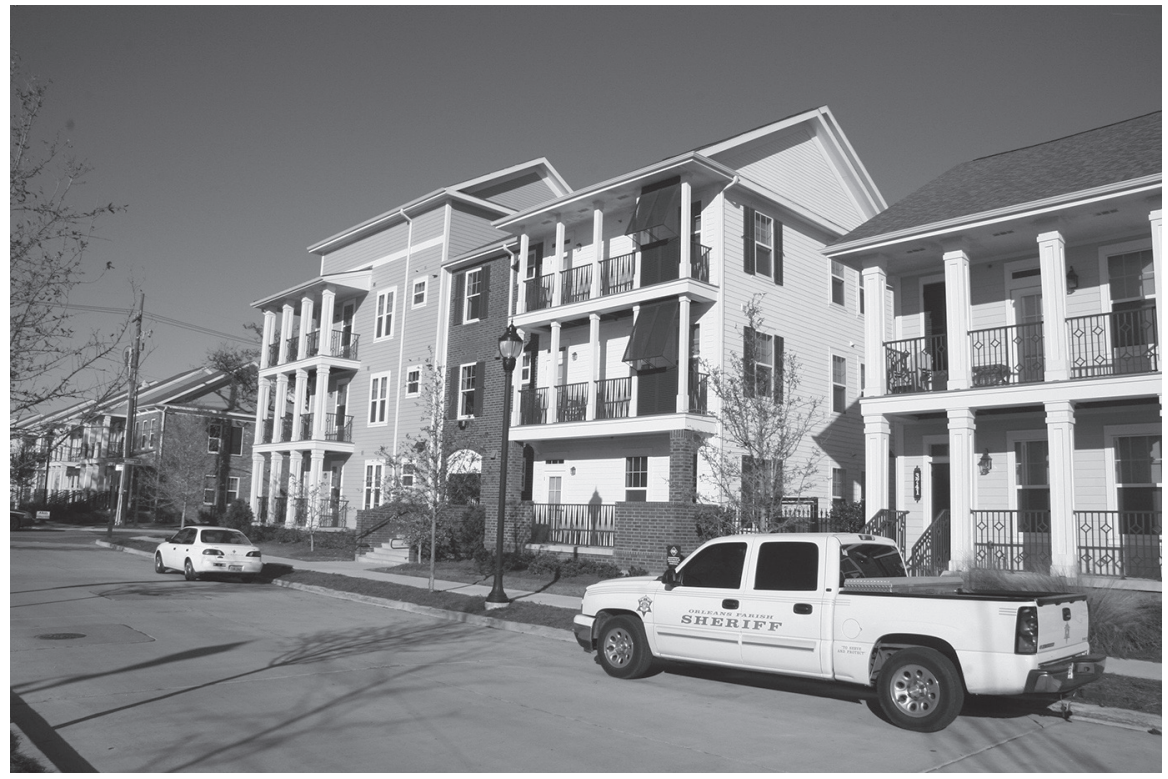

By August 2011 many residents had not returned. Among the former residents of the "Big Four" public housing estates, roughly half-1512-of the 3077 households there before the storm had returned to the city. Roughly seven percent of these original families have returned to the four sites, including 70 families to Harmony Oaks (Reckdahl: 2006). The new developments may look historical, but they cater to the modern reality of private car ownership to a far greater degree than their predecessors on the sites. Thoroughfare streets have been re-established in some places while the rear areas of some residential zones have been formed into large parking lots (two design features which also facilitate enhanced surveillance and policing). Resembling many "New Urbanist" projects across the US, tenancy in Harmony Oaks requires adherence to regulations of a kind commonly found in more upper-class gated communities and aimed at controlling "anti-social" behaviour. Following interviews with returned residents, one observer reports on the outcomes, both positive and negative:

For instance, they said, at Harmony Oaks, residents can't use outside water to fill a kiddie pool or let their grandchildren run through the sprinkler. Nor can they dig up their backyards to plant gardens, a source of frustration for the sisters, who grew up helping their mother pick crates of strawberries and hampers of beans. But, on Saturday, just as Jennings worked up a head of steam about other nettlesome rules, including one that limits how many people can sit on a porch and when they can do it, a granddaughter toddled up to her, removed a pink pacifier and puckered her lips for a smooch. (Reckdahl 2006)

Crime, though considerably reduced on the estate, has returned-and by some accounts has equalled or exceeded pre-storm rates-across broader swathes of the city. Arguably, in terms of this one indicator of community security and well-being, New Orleans has itself become "The Project" within which Harmony Oaks and the other housing estates (Fig. 5) are an ideally conceived and just partly realised reserve of relative tranquillity (Naughton 2006: 230). 


\section{Conclusion}

The destruction of large parts of New Orleans in 2005 sparked interest in reviving historical building forms, with many, like the timber-framed shotgun house, having been destroyed or hastily condemned after the inundation. However, questions arise over just what was being revived. Does the attention given to a single building type, row of shotgun houses, or a sprinkling of homes designed as contemporary "updates" on vernacular or historicist styles, ignore bigger issues relating to the reconstruction of entire urban districts, the return of their inhabitants and the accommodation of diverse needs and desires for community? For instance, is it historically anachronistic and possibly irresponsible to focus on rebuilding districts like the Lower Ninth Ward, when their abandonment and rehousing of former residents elsewhere is more likely to reduce overall urban vulnerability and enable communities to develop their own distinctive character, free from longstanding risks?

There are not only practical aspects to these and comparable efforts to revisit or adapt historical building types in order to restore urban infrastructure after a disaster, but also ethical or moralising agendas, in which notions of history, individual recollection and public memory are freely-and often unthinkingly-mixed. There is often an underlying imperative to repair shattered lives and restore historical continuities disrupted by catastrophic events; there is accompanying rhetoric describing elusive goals to facilitate individual emotional recovery and social cohesion by making the built environment 'whole' again.

Conceivably, one of the effects of this tendency is to highlight, but also obscure, boundaries between domains of social and psychological reasoning, so that memory becomes something less than precise-less amenable to analysis by one or other theory of the past, cognition or collective mnemonics. Rather, in these instances memory provides a humanist gloss, more or less explicit in reconstruction plans, that substantiates a range of ideological, economic and/or political agenda served by rebuilding.

Arguably, the wide variety of possibilities, concepts and terms for describing an architectural or building type-like such comparably abstract entities as community, place and memory-accounts for the conventional status of such terms in urban, architectural and disaster reconstruction discourses. Clearly, when urban disaster strikes, ambiguity may accommodate a mixture of motives for re-building, commemoration and social engineering. In the context of post-Katrina New Orleans, efforts to revive or reinstate and adapt the forms of historic housing were not only varied as aesthetic interventions (to revive, to adapt, etc.). They were also mixed in terms of underlying motives and social outcomes. Some efforts called upon the architectural history of New Orleans, in the attempt to restore or reinvigorate what was presumed to be the organic link between the city, its cultural heritage and built environment. Others called upon images of shotgun houses, French Quarter townhouses or Garden District cottages for their popular appeal or marketability, or for their connection to New Urbanist ideals and other prevailing planning movements. In each case, typological analysis (being a manner of descriptive classification) slides quickly into topological assertion: the study of places and the assumption that each place has a distinctive character that is potentially generative of building forms. Topology was once understood as, "The art of assisting the memory by associating the thing to be remembered with some place or building, the parts of which are well known.” (Oxford English Dictionary 1989) Observing the ambivalence of these terms and analyses raises possibilities for aesthetic, ethical and political criticism of particular recovery settings and scenarios. 


\section{References}

Allen, B. (2006). New Orleans and Katrina: One year later. Journal of Architectural Education, $60(1), 4$.

Ashlin, A. \& Ladle, R. (2007). Natural disasters and newspapers: Post-tsunami environmental discourse. Environmental Hazards, 7,330-41.

Clark, T. D. (1944). Pills, petticoats and plows. The Southern country store. Indianapolis and New York: Bobbs-Merrill Co.

Davis, M. (2002). Dead cities, and other tales. New York, NY: New Press.

Furedi, F. (2007). The changing meaning of disaster. Area, 39 (4), 482-489.

Gardner, T., Irwin, A., \& Peterson, C. W. (2009). No shelter from the storm: reclaiming the right to housing and protecting the health of vulnerable communities in post-Katrina New Orleans. Health and Human Rights, 11 (2), 101-114.

Glavovic, B. (2008). Katrina recovery experiences: Imperatives for building sustainable, hazardresilient communities. Paper delivered to the 4th International i-Rec Conference Building resilience: achieving effective post-disaster reconstruction. Christchurch, New Zealand. Retrieved from: http://www.resorgs.org.nz/irec2008/Papers/GlavovicB.pdf

Graham, S. (2003). Lessons in urbicide. New Left Review, 19, 63-78.

Herscher, A. (2006). American urbicide. Journal of Architectural Education, 60 (1), 18-20.

Huxtable, A. L. (1972). Will they ever finish Bruckner Boulevard? A primer on urbicide. New York, NY: Collier Books.

Kniffen, F. B. (1936). Louisiana house types. Annals of the Association of American Geographers, 26 (4) (December), 173-93.

Leach, A. (2010). What is architectural history? Cambridge, UK: Polity Press.

Mahoney, M. (1990). Law and racial geography: Public housing and the economy in New Orleans. Stanford Law Review, 42(5), 1251-1290.

Make it Right Foundation (2009). Building green. Retrieved from: http://www.makeitrightnola.org/ index.php/building_green/architecture/

Naughton, A. (2006). Trends in New Orleans psychogeography. Anthropology and Aesthetics, 49(50), 229-30.

Oxford English Dictionary (1989). Online version June 2012. Retrieved from: http://www.oed.com/view/Entry/203426

Reckdahl, K. (2006, Sunday August 21). New C. J. Peete complex is solid, shiny-but not as social, some residents say. The Times Picayune (New Orleans). Retrieved from: http://www.nola.com/ politics/index.ssf/2011/08/new_cj_peete_complex_is_solid.html

Schneider, J. \& Susser, I. (2003). Destruction and reconstruction in a globalized world. New York, NY: Berg.

Taylor, W. M. \& Levine, M. P. (2011). Prospects for an ethics of architecture. London and New York (NY): Routledge.

US Department of Housing and Urban Development (2007). Environmental Justice Study. C. J. Peete Housing Development New Orleans, Louisiana. US Risk Management: New Orleans. Retrieved from: http://www.hano.org/Documents/Environmental Justice Study Final/15060164 CJ Peete Env Justice Study Final.pdf

Verderber, S. (2010). Five years after - three New Orleans neighborhoods. Journal of Architectural Education 64(1), 107-120.

Vlach, J. M. (1976). The shotgun house: An African architectural legacy. Part I. Pioneer America 8 (1), 47-49.

Vogt, L. (1985). New Orleans houses. Gretna, LA: Pelican Publishing Company. 